\title{
The Dynamic Effect of Public Information on Liquidity: From the Perspective of Limited Attention
}

\author{
Tao Bing ${ }^{1}$ and Yian Cui ${ }^{2}$ \\ ${ }^{1}$ School of Finance, Capital University of Economics and Business, Beijing, China \\ ${ }^{2}$ Research Institute, Shenzhen Stock Exchange, Shenzhen, China \\ Correspondence should be addressed to Yian Cui; yacui@szse.cn
}

Received 13 May 2021; Accepted 12 June 2021; Published 28 June 2021

Academic Editor: Lei Xie

Copyright ( $) 2021$ Tao Bing and Yian Cui. This is an open access article distributed under the Creative Commons Attribution License, which permits unrestricted use, distribution, and reproduction in any medium, provided the original work is properly cited.

\begin{abstract}
The financial system is a complex system. The heterogeneous behaviors of investors further increase the degree of its complexity. In this paper, we develop a rational expectations equilibrium model to analyze the effect of public information on market efficiency and liquidity, especially in the market in which investors monitor the market imperfectly. When public information is partly reflected in equilibrium price or the uncertainty about the asset value is great, market efficiency increases with the increase of the precision of public information and the investors holding it. However, when the uncertainty about the fundamental value is small, the increase of the precision of public information worsens market liquidity. And in this market, with the increase of the investors acquiring public information, market liquidity first decreases and then increases. Overall, our results suggest that listed companies should disclose their information accurately by different channels as much as possible, and the regulators should enhance the supervision of information disclosure to enhance market efficiency and liquidity.
\end{abstract}

\section{Introduction}

Regulation rules in most countries require listed companies to disclose their information accurately and timely to the public. And the news providers, such as Thomson Reuters and Bloomberg, and the securities companies, release every type of financial news and the relevant information about the asset value. However, the news arrives at unscheduled times, and its frequency differs a lot (Gross-Klussmann and Hautsch) [1]. Investors could not get the news instantaneously because of their limited attention. And they need time to analyze the news to make the right decision. Consequently, the public information is firstly used by part of investors. Then, all investors acquire it, and the public information is fully reflected in the price. How does the public information affect the market liquidity and efficiency in this process?

In fact, investors' information is asymmetry in this process. Thus, part of the investors will acquire the arbitrage using their information advantage. And the others will improve their limited attention and speed up their information processing capacity to capture the news as soon as possible. In recent years, lots of strategies and algorithms have been designed with the rapid development of computer technology, such as the High Frequency Trading specializing in trading extremely fast on financial news, and the strategies based on the public sentiment spread in the Twitter and microblog. How does investing affect the market liquidity and efficiency? And what should the regulators do to realize the positive effect of public information on enhancing liquidity and efficiency?

To address these questions, we develop a two-period rational expectations equilibrium model with one risky asset. Risk-averse investors and liquidity investors exist in the market. Risk-averse investors also differ in private information. And they trade based on their information to maximize expected utility. In period 1, because of the limited attention and the difference in processing news, only part of the risk-averse investors capture the public information 
instantaneously after it is disclosed. Then, all risk-averse investors observe it in period 2 .

Focusing on period 1, we find that the price efficiency increases with the increase of the precision of public information and the investors capturing the public information. When the uncertainty of the asset value is great, the liquidity also increases with the two variables. However, when the uncertainty of the asset value is small, the liquidity decreases with the precision of public information. And when few investors capture the public information, the liquidity decreases with the increase of these investors; while more investors observe it, the liquidity increases with these investors. This is different with Han et al. [2]. The main reason is that the public information in this paper is firstly obtained by part of investors, while, in their paper, every investor could observe the public signal. Besides, since they endogenize the noise trading, the noise trading increases with the increase of the precision of public information, which worsens the price efficiency.

The, $\mathrm{n}$ we endogenize the public information acquisition. By comparing the benefit investing in the technology and the cost, investors choose to invest or not. The results show that the extra benefit of investing is higher for uninformed investors than for the investors with private signal. This is contradicting the learning complementarities in Easley et al. [3]. In fact, in their paper, the investors use the price signal, namely, the public signal, to predict the price, while, in this paper, investors use the public information to predict the fundamental value. Similar with their results, the four types of investors cannot coexist in the market. And the investors investing in the technology decrease with the increase of the cost.

At last, the results show that the regulators should require the listed companies to provide their information more accurately and timely to the public, especially disclosing their information by different channels as much as possible. And the regulators should give support to the companies investing in the technology and encourage more companies to develop the technology with the intent of decreasing the acquisition cost of investors.

This paper enriches the theoretical research on the implications of public signal for firm value, equilibrium price, market liquidity, and efficiency (see the surveys, Verrecchia [4] and Leuz and Wysocki [5]). In the framework of rational expectations equilibrium (REE), previous research has explored the implications of public signal for liquidity (Han et al. [2] and Chen et al. [6]), for price informativeness (Amador and Weill [7], Chen et al. [8], Han et al. [2]), and for information acquisition (Lundholm [9] and Easley et al. [3]). However, none of these studies pays attention to the process that public information is partly captured by the public. In their assumptions, all investors obtain the public information instantaneously. But with the development of financial markets, the process really plays an important role in market reactions to the public information (Dugast [10]). We investigate the implications of public information for liquidity and efficiency by considering this process.

\section{Literature Review}

Many theoretical studies have investigated the effect of public information on financial markets. Diamond and Verrecchia [11] show that releasing public information can improve market liquidity by reducing information asymmetry. Kim and Verrecchia [12] find that investors with heterogeneous information processing abilities have different reactions to public announcements. Then, the studies explore the effect of public information on other microstructure characteristics. For instance, Lambert et al. [13] show that the quality of public information can influence the cost of capital. Kondor [14] finds that when the correlation between the private information of different groups is sufficiently low, the public announcement can decrease the investors' disagreement about the fundamental value, but it increases the disagreement of the expected selling price among short-horizon traders. Han et al. [2] show that public information attracts more liquidity traders by reducing their expected trading loss. And this has a negative effect on information aggregation. When the information is endogenous, public information can crowd out the private information and attract more noise trading.

However, the public information in these studies is acquired by all investors once after it is released. Some empirical studies have documented that investors do not receive public information at the same time. For instance, Tetlock [15] uses a comprehensive data set on all type of news to investigate the effect of public information on stock returns. The research shows that public information plays a key role in informing certain traders in advance. DellaVigna and Pollet [16] show that the underreaction to public information caused by investors' limited attention could explain postearnings announcement drift.

In fact, the effect of limited attention on traders' decision-making has been a fairly new research topic. Johnston and Pashler [17] confirm that the central cognitive processing capacity of the human brain has its limits. Peng [18], Peng and Xiong [19], and Van Nieuwerburgh and Veldkamp $[20,21]$ build theories to explore traders' limit attention on portfolio diversification and asset prices. The intuition is straightforward. The more that investors pay attention to the asset, the more precise the investors' information about the future payoff. And several papers analyze the effect of limited attention on traders' strategy. For instance, Biais and Weill [22] describe the dynamic of order book after a liquidity shock in the market that investors cannot monitor markets continuously. Dugast [10] shows that prices reflect unscheduled news with delay because investors monitor the market imperfectly as a result of their limited attention. Following news arrival, the trading volume and price variability show a positive covariance. And this covariance declines with the news arrival frequency. This paper contributes to the literature by discussing the effect of public information on market dynamics in a market that both informed and uninformed investors monitor the market imperfectly. 


\section{The Model}

3.1. The Model Assumptions. Consider a two-period market, in which a risky asset (of liquidation value $\widetilde{v}$ ) is traded by a continuum of risk-averse investors and liquidity investors. $\widetilde{v}$ is normally distributed $\widetilde{v} \sim N\left(\bar{v},\left(1 / \rho_{v}\right)\right)$, where $\bar{v}>0$ and $\rho_{v}>0$, and traded at a price $\widetilde{p}_{t}(t=0,1,2,3)$ with $\widetilde{p}_{0}=\bar{v}$ and $\widetilde{p}_{3}=v$.

The risk-averse investors have constant absolute risk aversion (CARA) utility with a risk-averse coefficient of $\gamma>0$. Risk-averse investors are categorized into two groups according to whether they have the private signal on $\widetilde{v}$ in the form of $\widetilde{s}_{i}=\widetilde{v}+\widetilde{\epsilon}_{i}$ in period 1 with $\widetilde{\epsilon}_{i} \sim N\left(0,\left(1 / \rho_{\epsilon}\right)\right)$ and $\rho_{\epsilon}>0$. We call the investors acquiring private signal $\widetilde{s}_{i}$ informed investors with a exogenous mass of $\mu$, and the others private signal uninformed investors with a mass of $1-\mu$. A private signal informed investor $i$ recalls $\widetilde{s}_{i}$ in period 2 .

We further assume that, in period, 1 a signal $\tilde{y}=\widetilde{v}+\widetilde{\eta}$ is publicly disclosed to the market, where $\widetilde{\eta} \sim N\left(0,\left(1 / \rho_{\eta}\right)\right)$, $\rho_{\eta}>0$. However, because of the limited attention and the different information processing capacity, part of risk-averse investors could not acquire the public information in period 1. They can only acquire it in period 2 . To improve their acquiring ability, they can invest in a technology at a cost $c_{L}$. We call the investors acquiring the technology public information informed investors, and the others public information uninformed investors.

According to the information type, the investors in period 1 could be defined to four groups: $n$-investors, $l$-investors, $p$-investors, and $p l$-investors ( $n$ : uninformed investors, $l$ : technology of improving limited attention, $p$ : private information) ( $n$-investors are uninformed investors, and their information set is $I_{i 1}=\left\{\widetilde{p}_{1}\right\} . l$-investors acquire public news $\tilde{y}$, and their information set is $I_{i 1}=\left\{\widetilde{p}_{1}, \tilde{y}\right\}$. $p$-investors acquire private signal, and their information set is $I_{i 1}=\left\{\widetilde{p}_{1}, \widetilde{s}_{i}\right\}$. And $p l$-investors acquire public news and private signal, and their information set is $\left.I_{i 1}=\left\{\tilde{p}_{1}, \tilde{y}, \widetilde{s}_{i}\right\}\right)$. The mass of each type of investors is $\mu_{n}, \mu_{l}, \mu_{p}$ and $\mu_{p l}$, satisfying $\mu_{n}+\mu_{l}+\mu_{p}+\mu_{p l}=1, \quad \mu_{n}+\mu_{l}=1-\mu \quad$ and $\mu_{p}+\mu_{p l}=\mu$. In Section 3.3, we endogenize the mass of investors investing in the technology (here, we do not endogenize the informed investors' private signal acquisition decision). In period 2 , all the risk-averse investors get $\tilde{y}$, and they are distinguished by getting private signal or not. For simplicity, we call the investor with $\widetilde{s}_{i}$ informed investors, and the other risk-averse investors uninformed investors (in period 2, the information set of informed traders is $I_{i 2}=\left\{\tilde{p}_{1}, \tilde{p}_{2}, \tilde{y}, \widetilde{s}_{i}\right\}$ and the information set of uninformed traders is $\left.I_{i 2}=\left\{\tilde{p}_{1}, \widetilde{p}_{2}, \tilde{y}\right\}\right)$. The mass of informed investors and uninformed investors is $\mu$ and $1-\mu$.

In period $t$, the demand function of risk-averse investors $i$ with information set $I_{i t}$ is $D_{i t}\left(I_{i t}\right)$, and the net demand of liquidity investors is $\tilde{x}_{t} \sim N\left(0,\left(1 / \rho_{x_{t}}\right)\right)$. All variables in set $\left\{\widetilde{v},\left\{\widetilde{x}_{t}\right\}_{t \in\{1,2\}},\left\{\widetilde{\varepsilon}_{i}\right\}, \widetilde{\eta}\right\}$ are mutually independent.

3.2. The Market Equilibrium. The equilibrium concept here is the rational expectations equilibrium [23] involving the optimal trading strategy. In a linear REE, investors conjecture about the following price function:

$$
\widetilde{p}_{t}=\alpha_{0 t}+\alpha_{y t} \tilde{y}+\alpha_{v t} \tilde{v}+\alpha_{x t} \tilde{x}_{t}+\alpha_{p_{t-1}} \tilde{p}_{t-1},
$$

where the coefficients will be endogenously determined (in period $1, \widetilde{p}_{0}=\bar{v}$ is included in the constant $\alpha_{01}$ ). The market equilibrium in this paper is as follows.

Definition 1. Given the fractions of four type investors, the price information $\widetilde{p}_{t}$ and investors' demand functions $D_{i t}\left(I_{i t}\right)$ constitute an REE if (1) $D_{i t}\left(I_{i t}\right)$ maximizes the expected utility of trader $i$ conditional on their information given the price $\widetilde{p}_{t}$ and (2) the market clearing by the total demand equals the total supply, i.e., $\int_{0}^{1} D_{i t} \mathrm{~d} i+x_{t}=0$.

By maximizing investors' conditional expected utility function, we could obtain that

$$
D_{i t}\left(I_{i t}\right)=\frac{E\left(\widetilde{v}-\widetilde{p}_{t} \mid I_{i t}\right)}{\gamma \operatorname{Var}\left(\widetilde{v}-\widetilde{p}_{t} \mid I_{i t}\right)} .
$$

Note that since part of investors does not get $\tilde{y}$ in period 1 , the information in the price differs with the investor groups. For $p$-investors and $n$-investors, $\widetilde{p}_{1}$ is equivalent to the signal $\widetilde{s}_{p_{11}}=\left(\left(\widetilde{p}_{1}-\alpha_{01}\right) /\left(\alpha_{v 1}+\alpha_{y 1}\right)\right)=\widetilde{v}+\left(\alpha_{x 1} /\left(\alpha_{v 1}+\right.\right.$ $\left.\left.\alpha_{y 1}\right)\right) \tilde{x}_{1}+\left(\alpha_{y 1} /\left(\alpha_{v 1}+\alpha_{y 1}\right)\right) \tilde{\eta}$, which, conditional on $\tilde{v}$, is normally distributed with mean $\widetilde{v}$ and precision $\rho_{s_{p_{11}}}^{-1}$, where $\rho_{s_{p_{11}}}=\left(\left(\alpha_{v 1}+\alpha_{y 1}\right)^{2} \rho_{\eta} \rho_{x_{1}}\right) /\left(\alpha_{x 1}^{2} \rho_{\eta}+\alpha_{y 1}^{2} \rho_{x_{1}}\right)$. And for $p l$-investors and $l$-investors, $\widetilde{p}_{1}$ is equivalent to the signal $\widetilde{s}_{p_{12}}=\left(\left(\widetilde{p}_{1}-\alpha_{01}-\alpha_{y 1} \tilde{y}\right) / \alpha_{v 1}\right)=\widetilde{v}+\left(\alpha_{x 1} / \alpha_{v 1}\right) \widetilde{x}_{1}$, which, conditional on $\widetilde{v}$, is normally distributed with mean $\widetilde{v}$ and precision $\rho_{s_{p_{12}}}^{-1}$, where $\rho_{s_{p_{12}}}=\left(\alpha_{v 1} / \alpha_{x 1}\right)^{2} \rho_{x_{1}}$. In period 2 , all investors observe the public information, and then $\widetilde{p}_{2}$ is equivalent to $\widetilde{s}_{p_{2}}=\left(\left(\widetilde{p}_{2}-\alpha_{02}-\alpha_{p_{1}} \widetilde{p}_{1}-\right.\right.$ $\left.\left.\alpha_{y 2} \tilde{y}\right) / \alpha_{v 2}\right)=\tilde{v}+\left(\alpha_{x 2} / \alpha_{v 2}\right) \tilde{x}_{2}$, which, conditional on $\widetilde{v}$, is normally distributed with mean $\widetilde{v}$ and precision $\rho_{s_{p_{2}}}^{-1}$, where $\rho_{s_{p_{2}}}=\left(\alpha_{v 2} / \alpha_{x 2}\right)^{2} \rho_{x_{2}}$.

${ }^{p_{2}}$ Substituting $D_{i t}\left(I_{i t}\right)$ in equation (2), we can determine the coefficients in equation (1), which is shown in Proposition 1 .

Proposition 1. There exists a unique linear equilibrium with the price function

$$
\widetilde{p}_{t}=\alpha_{0 t}+\alpha_{y t} \tilde{y}+\alpha_{v t} \tilde{v}+\alpha_{x t} \tilde{x}_{t}+\alpha_{p_{t-1}} \tilde{p}_{t-1},
$$

where the coefficients are endogenously determined and shown in the appendix.

Next, we analyze the effect of two public information variables, the precision of public information $\rho_{\eta}$ and the mass of investors obtaining public information $\mathrm{TB}_{2}$ (i.e., $\left.\mathrm{TB}_{2}=\mu_{l}+\mu_{p l}\right)$, on the price informativeness and liquidity.

In period 1 , since $n$-investors and $p$-investors cannot observe $\tilde{y}$, the price informativeness is $I_{1}=\left(\operatorname{var}\left(\widetilde{v} \mid \widetilde{p}_{1}\right)\right)^{-1}$. Applying Bayes rules yields $I_{1}=\rho_{v}+\rho_{s_{p_{1}}}$. In period 2, all investors observe $\tilde{y}$, and then the price informativeness is $I_{2}=\left(\operatorname{var}\left(\widetilde{v} \mid \widetilde{p}_{1}, \widetilde{p}_{2}, \widetilde{y}\right)\right)^{-1}$, and $I_{2}=\rho_{v}+\rho_{s_{p_{12}}}+\rho_{s_{p_{2}}}+\rho_{\eta}$. 
Corollary 1. $\left(\partial I_{1} / \partial \rho_{\eta}\right)>0, \quad\left(\partial I_{1} / \partial T B_{2}\right)>0, \quad\left(\partial I_{2} / \partial \rho_{\eta}\right)>0$, $\left(\partial I_{2} / \partial T B_{2}\right)=0$.

It is straightforward that, in period 1 , as more investors get the public information, and the precision of the public information increases, more information is brought into the price by $l$ and $p l$-investors. Thus, $\left(\partial I_{1} / \partial \rho_{\eta}\right)>0$ and $\left(\partial I_{1} / \partial \mathrm{TB}_{2}\right)>0$. Similarly, as $\rho_{\eta}$ increases, $I_{2}$ increases. Since all investors obtain $\tilde{y}$ in period $2, \mathrm{~TB}_{2}$ has no effect on $I_{2}$.

$\alpha_{x t}$ in Proposition 1 reflects how liquidity trading influences the equilibrium price; i.e., $1 / \alpha_{x t}$ measures the market depth. A greater $\alpha_{x t}$ means that liquidity trading has a greater influence on price. Therefore, market liquidity LIQ is measured by $1 / \alpha_{x t}$.

Computations show that market liquidity in period 1 , $\mathrm{LIQ}_{1}$, can be decomposed into two components: the direct effect and the indirect effect $\left(\operatorname{LIQ}_{1}=\left(\alpha_{v 1} / \alpha_{x 1}\right)[1+\right.$ $\left.\left(\alpha_{y 1} / \alpha_{v 1}\right)\right]\left(1+\left(\rho_{v} /\left(\mathrm{WAP}-\rho_{v}\right)\right)\right)$, where WAP $=\mu_{n} \operatorname{var}^{-1}$ $\left(\widetilde{v} \mid \widetilde{p}_{1}\right)+\mu_{p} \operatorname{var}^{-1}\left(\widetilde{v} \mid \widetilde{p}_{1}, \widetilde{s}_{i}\right)+\mu_{l} \operatorname{var}^{-1}\left(\widetilde{v} \mid \widetilde{p}_{1}, \widetilde{y}\right)+\mu_{p l} \operatorname{var}^{-} 1(\widetilde{v} \mid$ $\left.\widetilde{p}_{1}, \widetilde{s}_{i}, \widetilde{y}\right) \cdot \alpha_{y 1} / \alpha_{v 1}$ is the ratio of the effect of public news on equilibrium price and the effect of fundamental value on equilibrium price. The stronger the public news, the more the liquidity. We call the term $1+\left(\alpha_{y 1} / \alpha_{v 1}\right)$ the component of the public news direct effect. WAP is the weighted average of the precision that all investors' expectation to the fundamental value is based on their information, and it measures the rational traders' average market precision on asset. The greater it is, the greater the adverse risk faced by the investors without public news is. Thus, the liquidity provided by the public news uninformed traders decreases. We call it the component of the public news indirect effect). The direct component measures the positive effect of public information on liquidity due to the increase of the precision of public information and the investors with public information, whereas the indirect component mainly measures the adverse selection risk of public information on liquidity. In fact, as $\rho_{\eta}$ increases, investors expect the fundamental value more precisely. Then, liquidity decreases because of the increase of adverse selection risk. When $\mathrm{TB}_{2}$ increases, more investors trade based on the public information, and the price informativeness increases (as stated in Corollary 1). The adverse selection risk increases. However, the weight (the mass of $n$ and $p$ type investors decreases) of $\rho_{s_{p_{11}}}$ decreases. The adverse selection risk decreases. Therefore, the effect of $\mathrm{TB}_{2}$ on liquidity is not determined. The total effect of public information variables on $\mathrm{LIQ}_{1}$ is determined by the relative strength of the two effects.

As the public information is the new information, its effect on liquidity may be related to the previous uncertainty level of the asset fundamental. The next corollary shows the effect of $\rho_{\eta}$ and $\mathrm{TB}_{2}$ on liquidity.

Corollary 2. (1) For sufficiently small $\rho_{v},\left(\partial L I Q_{1} / \partial \rho_{\eta}\right)>0$. And for sufficiently large $\rho_{v},\left(\partial L I Q_{1} / \partial \rho_{\eta}\right)<0$. (2) For sufficiently small $\rho_{v},\left(\partial L I Q_{1} / \partial T B_{2}\right)>0$. For sufficiently large $\rho_{v}$, when $\quad T B_{2} \in\left[0, T B_{2}^{*}\right], \quad\left(\partial L I Q_{1} / \partial T B_{2}\right)<0 ; \quad$ while $T B_{2} \in\left[T B_{2}^{*}, 1\right],\left(\partial L I Q_{1} / \partial T B_{2}\right)>0$.



FIGURE 1: The relation between $\rho_{\eta}$ and $\mathrm{LIQ}_{1}$.

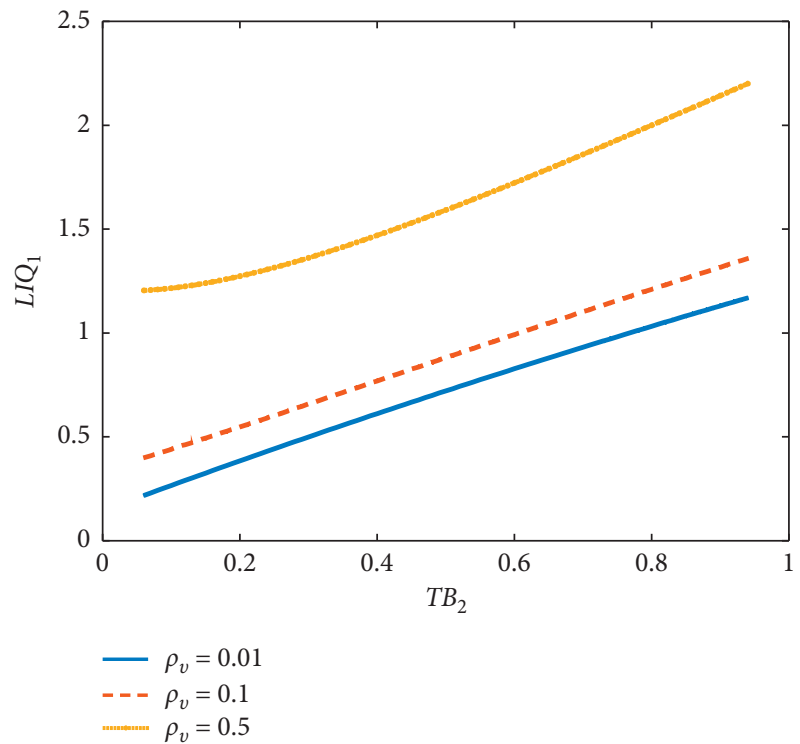

FIgure 2: The relation between $\mathrm{TB}_{2}$ and $\mathrm{LIQ}_{1}$ when $\rho_{v}$ is small.

Figure 1 describes the relation between $\rho_{\eta}$ and $\mathrm{LIQ}_{1}$ with different $\rho_{v}$. Figures 2 and 3 show the relation between $\mathrm{TB}_{2}$ and $\mathrm{LIQ}_{1}$ with different $\rho_{v}$. When $\rho_{v}$ is sufficiently small, the uncertainty about the fundamental value is great. As $\rho_{\eta}$ and $\mathrm{TB}_{2}$ increase, trading based on public information transfers more information to the market. The public information direct effect dominates the public information indirect effect; thus, liquidity increases.

However, when $\rho_{v}$ is sufficiently large, the effect of $\rho_{\eta}$ and $\mathrm{TB}_{2}$ on liquidity is different. When the uncertainty about the fundamental value is small, as $\rho_{\eta}$ increases, the adverse selection risk becomes stronger. The public information indirect effect dominates the public information direct effect; thus, liquidity decreases. Since $\mathrm{TB}_{2}$ affects $\rho_{s_{p_{11}}}$, the net weighted average of investors' expectation precision 


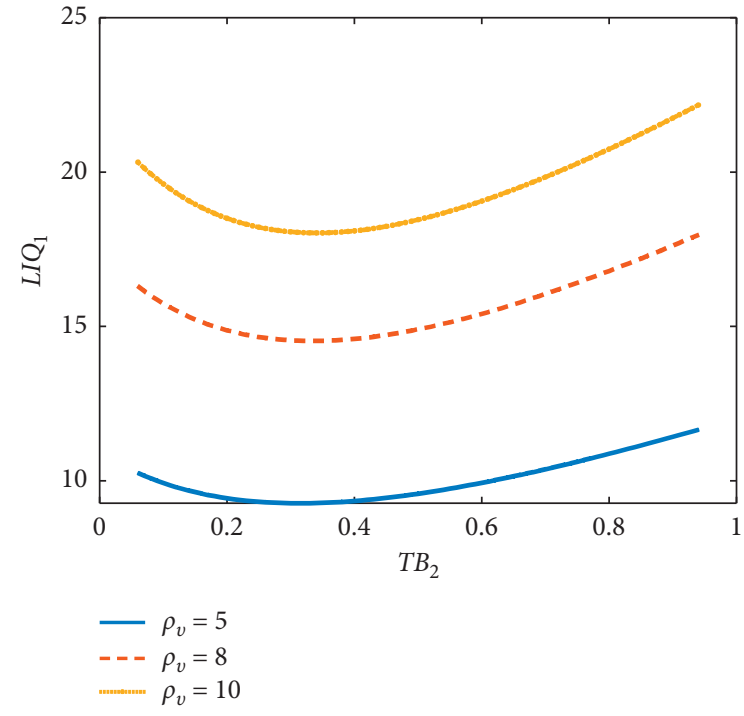

FIgure 3: The relation between $\mathrm{TB}_{2}$ and $\mathrm{LIQ}_{1}$ when $\rho_{v}$ is large.

increases with the increase of $\mathrm{TB}_{2}$; i.e., the adverse selection risk increases. Thus, the liquidity decreases. While $\mathrm{TB}_{2}$ is large, $\rho_{s_{p}}$ increases more, and then, the net weighted average of investors' expectation precision decreases with the increase of $\mathrm{TB}_{2}$; i.e., the adverse selection risk decreases. Thus, liquidity increases. Besides, Figure 3 also shows that, with the increase of $\rho_{v}, \mathrm{~TB}_{2}^{*}$ increases.

Since, in period 2 , all investors obtain $\tilde{y}$, the liquidity increases with the increase of its precision. And the mass of investors acquiring $\tilde{y}$ is constant; thus, it does not affect the $\mathrm{LIQ}_{2}$.

Corollary 3. (1) $\left(\partial L I Q_{2} / \partial \rho_{\eta}\right)>0$. (2) $\left(\partial L I Q_{2} / \partial T B_{2}\right)=0$.

3.3. Endogenous Public Information Acquisition. We now derive the equilibrium demand for the technology, namely, equilibrium masses, $\mu_{l}^{*}$ and $\mu_{p l}^{*}$, of $l$-investors and $p l$-investors. Assume the $\operatorname{cost} c_{L}$ is constant (this assumption has its realistic foundation, and it has been modeled in some research. For example, some exchanges, such as NYSE, NASDAQ, and Deutsche Bourse, have sold their market data before public information appears. Easely et al. [3] model this practice and analyze its effect on price discovery and market quality. Biais and Weill [22] build an equilibrium model, in which fast traders have extremely rapid connections with the markets, and they can receive price information (namely, the public information) once it is disclosed. And slow traders could invest in fast trading technology to improve their information acquisition ability). Since all investors in period 2 will obtain the public information, the difference of the benefit between investors acquiring the public information or not is only reflected in period 1 .

For an uninformed trader, the benefit, $B_{u}$, of investing in the technology is the difference between the indirect utility of a $l$-investor and his indirect utility. Calculations show that the benefit is

$$
B_{u}=\frac{1}{2 \gamma} \log \left(\frac{\operatorname{Var}\left(\widetilde{v}-\widetilde{p}_{1} \mid \widetilde{p}_{1}\right)}{\operatorname{Var}\left(\widetilde{v}-\widetilde{p}_{1} \mid \widetilde{p}_{1}, \tilde{y}\right)}\right)=\frac{1}{2 \gamma} \log \left(\frac{\rho_{v}+\rho_{s_{p_{12}}}+\rho_{\eta}}{\rho_{v}+\rho_{s_{p_{11}}}}\right) .
$$

Similarly, for an investor with private signal, the benefit, $B_{i}$, of investing in the technology is

$$
B_{i}=\frac{1}{2 \gamma} \log \left(\frac{\operatorname{Var}\left(\widetilde{v}-\widetilde{p}_{1} \mid \widetilde{p}_{1}, \widetilde{s}_{i}\right)}{\operatorname{Var}\left(\widetilde{v}-\widetilde{p}_{1} \mid \widetilde{p}_{1}, \tilde{y}, \widetilde{s}_{i}\right)}\right)=\frac{1}{2 \gamma} \log \left(\frac{\rho_{v}+\rho_{s_{p_{12}}}+\rho_{\varepsilon}+\rho_{\eta}}{\rho_{v}+\rho_{s_{p_{11}}}+\rho_{\varepsilon}}\right) \text {. }
$$

Direct computations show that $\rho_{s_{p_{11}}}+\rho_{\eta}>\rho_{s_{p_{1}}}$. In fact, investors with more information can expect the asset value with a higher precision $\left(\operatorname{Var}\left(\widetilde{v}-\widetilde{p}_{1} \mid \widetilde{p}_{1}, \widetilde{y}\right)<\operatorname{Var}\left(\widetilde{v}-\widetilde{p}_{1} \mid \widetilde{p}_{1}\right)\right.$ or $\left.\operatorname{Var}\left(\widetilde{v}-\widetilde{p}_{1} \mid \widetilde{p}_{1}, \widetilde{y}, \widetilde{s}_{i}\right)<\operatorname{Var}\left(\widetilde{v}-\widetilde{p}_{1} \mid \widetilde{p}_{1}, \widetilde{s}_{i}\right)\right)$. Then, $B_{u}>0$ and $B_{i}>0$.

By $\rho_{s_{p_{2}}}+\rho_{\eta}>\rho_{s_{p_{11}}}$, we also obtain that $B_{u}>B_{i}$. Thus, we have the following corollary.

Corollary 4. The extra benefit of observing public information $\tilde{y}$ is higher for $n$-investors than for p-investors.

$$
\begin{aligned}
& \rho_{s_{p_{12}}}+\rho_{\eta}>\rho_{s_{p_{11}}}, \frac{1}{2 \gamma} \log \left(\frac{\operatorname{Var}\left(\widetilde{v}-\tilde{p}_{1} \mid \tilde{p}_{1}\right)}{\operatorname{Var}\left(\widetilde{v}-\widetilde{p}_{1} \mid \tilde{p}_{1}, \widetilde{s}_{i}\right)}\right)>\frac{1}{2 \gamma} \log \left(\frac{\operatorname{Var}\left(\tilde{v}-\tilde{p}_{1} \mid \tilde{p}_{1}, \tilde{y}\right)}{\operatorname{Var}\left(\widetilde{v}-\widetilde{p}_{1} \mid \tilde{p}_{1}, \tilde{y}, \widetilde{s}_{i}\right)}\right) \\
& B_{u}-c_{L}, B_{i}-c_{L}, B_{i}\left(\mu_{l}, \mu_{p l}\right), B_{u}\left(\mu_{l}, \mu_{p l}\right), \mu_{l}^{*}, \mu_{p l}^{*}, B_{u}\left(\mu_{l}^{*}, \mu_{p l}^{*}\right)-c_{L}=0 \\
& B_{i}\left(\mu_{l}^{*}, \mu_{p l}^{*}\right)-c_{L}=0, \quad 0<\mu_{l}^{*}<1-\mu, 0<\mu_{p l}^{*}<\mu, B_{u}\left(\mu_{l}^{*}, \mu_{p l}^{*}\right)=c_{L}=B_{i}\left(\mu_{l}^{*}, \mu_{p l}^{*}\right) \\
& B_{u}\left(\mu_{l}, \mu_{p l}\right)>B_{i}\left(\mu_{l}, \mu_{p l}\right) .
\end{aligned}
$$

Remark 1. Assume that investors can also choose to acquire private signal. Then, by $\rho_{s_{p, 2}}+\rho_{\eta}>\rho_{s_{p 11}}$, we have $1 / 2 \gamma \log$ $\left(\operatorname{Var}\left(\widetilde{v}-\widetilde{p}_{1} \mid \widetilde{p}_{1}\right) / \operatorname{Var}\left(\widetilde{v}-\widetilde{p}_{1} \mid \widetilde{p}_{1}, \widetilde{s}_{i}\right)\right)>\quad 1 / 2 \gamma \log \quad(\operatorname{Var}(\widetilde{v}-$ $\left.\left.\widetilde{p}_{1} \mid \widetilde{p}_{1}, \tilde{y}\right) / \operatorname{Var}\left(\widetilde{v}-\widetilde{p}_{1} \mid \widetilde{p}_{1}, \tilde{y}, \widetilde{s}_{i}\right)\right)$, which shows that the extra benefit of acquiring private information $\widetilde{s}_{i}$ is higher for $n$-investors than for $l$-investors. Thus, the marginal benefit of acquiring an additional form of information is smaller for investors who have already obtained some information than for those who have not. In other words, the two pieces of information $\widetilde{s}_{i}$ and $\tilde{y}$ are substitutable. Investors without 
information have a great incentive to acquire additional information than those with some information. This occurs because both $\widetilde{s}_{i}$ and $\tilde{y}$ include the same information about the fundamental value $\widetilde{v}$.

An $n$-investor ( $p$-investor) investing in the technology obtains a net expected profit of $B_{u}-c_{L}\left(B_{i}-c_{L}\right)$. No investors will choose to invest if $B_{u}-c_{L}<0$ and $B_{i}-c_{L}<0$. Computations show that $B_{u}$ and $B_{i}$ decrease with $\mu_{l}$ and $\mu_{p l}$ (in the following, regard $B_{u}$ and $B_{i}$ as the function of $\mu_{p l}$ and $\mu_{l}$ to determine the equilibrium mass, i.e., $B_{i}\left(\mu_{l}, \mu_{p l}\right)$ and $\left.B_{u}\left(\mu_{l}, \mu_{p l}\right)\right)$. Because of the monotone decreasing, $\mu_{l}^{*}$ and $\mu_{p l}^{*}$ can be determined by solving $B_{u}\left(\mu_{l}^{*}, \mu_{p l}^{*}\right)-c_{L}=0$ and $B_{i}\left(\mu_{l}^{*}, \mu_{p l}^{*}\right)-c_{L}=0$.

Note that, in equilibrium, the four investor types cannot be in the market at the same time. In fact, assume there are four types of investors in the market; i.e., there exist $\mu_{l}^{*}$ and $\mu_{p l}^{*}$ satisfying $0<\mu_{l}^{*}<1-\mu$ and $0<\mu_{p l}^{*}<\mu$. Then, we have $B_{u}\left(\mu_{l}^{*}, \mu_{p l}^{*}\right)=c_{L}=B_{i}\left(\mu_{l}^{*}, \mu_{p l}^{*}\right)$. However, this is contradicting with $B_{u}\left(\mu_{l}, \mu_{p l}\right)>B_{i}\left(\mu_{l}, \mu_{p l}\right)$, for any $\mu_{l}$ and $\mu_{p l}$. Hence, we have the following corollary.

Corollary 5. In the market, all four groups of investors cannot coexist.

Using the above corollary and the equilibrium condition, we have the following results based on the different level of $c_{L}$ :

Proposition 2. The equilibrium mass of each type of investors is as follows:

(1) When $c_{L}<\left.B_{i}\left(\mu_{l}, \mu_{p l}\right)\right|_{\mu_{p l}=\mu, \mu_{l}=1-\mu}$, all $n$-investors and $p$-investors invest in the technology

(2) When $\left.B_{i}\left(\mu_{l}, \mu_{p l}\right)\right|_{\mu_{p l}=\mu, \mu_{l}=1-\mu}<c_{L}<B_{i}\left(\mu_{l}, \mu_{p l}\right)$ $\left.\right|_{\mu_{p l}=0, \mu_{l}=1-\mu}$ all c-investors invest in the technology, whereas a $\mu_{p l}^{*}$ fraction of $p$-investors invest in the technology (the details of $\mu_{p l}^{*}$ in case (2) and $\mu_{l}^{*}$ in case (4) are given in Appendix)

(3) When $\left.B_{i}\left(\mu_{l}, \mu_{p l}\right)\right|_{\mu_{p l}=0, \mu_{l}=1-\mu}<c_{L}<B_{u}\left(\mu_{l}, \mu_{p l}\right)$ $\left.\right|_{\mu_{p l}=0, \mu_{l}=1-\mu}$, all $n$-investors invest in the technology, whereas all $p$-investors do not invest in the technology

(4) When $\left.B_{u}\left(\mu_{l}, \mu_{p l}\right)\right|_{\mu_{p l}=0, \mu_{l}=1-\mu}<c_{L}<B_{u}\left(\mu_{l}, \mu_{p l}\right)$ $\left.\right|_{\mu_{p l}=0, \mu_{l}=0}$, all $p$-investors do not invest in the technology, whereas a $\mu_{l}^{*}$ fraction of $n$-investors invest in the technology

(5) When $\left.B_{u}\left(\mu_{l}, \mu_{p l}\right)\right|_{\mu_{p l}=0, \mu_{l}=0}<c_{L}$, all $n$-investors and p-investors do not invest in the technology

Proposition 2 implies that the population of investors investing in the technology is negatively related to the cost. Trivially, when $c_{L}$ is equal to 0 or smaller than $\left.B_{i}\left(\mu_{l}, \mu_{p l}\right)\right|_{\mu_{p l}=0, \mu_{l}=1-\mu}$, every investor invests to acquire the public information immediately. There are only two types of investors: l-investors and pl-investors.

Since $B_{u}>B_{i}, n$-investors have more incentive to invest in the technology compared with $p$-investors. When $c_{L}$ increases above $\left.B_{i}\left(\mu_{l}, \mu_{p l}\right)\right|_{\mu_{p l}=0, \mu_{l}=1-\mu}$, part of $p$-investors first choose not to invest. As $c_{L}$ increases, more $\mathrm{p}$-investors will keep their current steady. And there are three types of investors in the market: $p$-investors, $p$-investors, and $l$-investors. Then, when $c_{L}$ increases to $\left.B_{i}\left(\mu_{l}, \mu_{p l}\right)\right|_{\mu_{p l}=0, \mu_{l}=1-\mu}$, all $p$-investors will choose not to invest. However, in this interval of $c_{L}$, all $n$-investors become $l$-investors. Note that when $c_{L}$ belongs to $\left[\left.B_{i}\left(\mu_{l}, \mu_{p l}\right)\right|_{\mu_{p l}=0, \mu_{l}=1-\mu},\left.B_{u}\left(\mu_{l}, \mu_{p l}\right)\right|_{\mu_{p l}=0, \mu_{l}=1-\mu}\right]$, all $p$-investors will choose not to invest, and all $n$-investors will invest. Now, there are only $p$-investors and $l$-investors in the market.

Once $c_{L}$ increases above $\left.B_{u}\left(\mu_{l}, \mu_{p l}\right)\right|_{\mu_{p l}=0, \mu_{l}=1-\mu}$, part of $n$-investors will choose to not invest, and all $p$-investors do not invest. And there are three types of investors in the market: $n$-investors, $l$-investors, and $p$-investors. After $c_{L}$ reaches $\left.B_{u}\left(\mu_{l}, \mu_{p l}\right)\right|_{\mu_{p l}=0, \mu_{l}=0}$, no investors will invest in the technology. And there are only $n$-investors and $p$-investors in the market.

3.4. Policy Implications. Our results show that, with the increase of the precision of public information, the liquidity increases (the underlying hypothesis is that public information is acquired by most investors. This is true in $r$ reality). In fact, the public information can be divided into two parts: the trading information from exchange, such as the volume and price, and the information from the listed companies, such as the accounting information and management information. We will give some policy suggestions from these two aspects. For the trading information, some exchanges such as US exchanges require trades, and amounts must be reported in real time. Our results show that the price informativeness increases with the increase of the precision of public information and the quantities of traders acquiring public information. Therefore, it is necessary to disclose more trading information to enhance price discovery.

For the public information related to the business of listed companies, the regulation rules in many countries, such as the Measures for the Administration of Information Disclosure of Listed Companies (Revised) (2020) in China, the Sarbanes-Oxley Act (2002), and the Dodd-Frank Act (2010) in the United States, have required the listed companies to strengthen information disclosure truthfully, accurately, completely, and timely to the public. The main purpose of these rules' intent is to improve market transparency and enhance market efficiency and liquidity. However, the results in this paper show that when the public information is just disclosed, these goals may not be achieved simultaneously. The news needs time to be fully reflected in equilibrium price. The regulators should be patient with the process. As stated in Corollary 2, sometimes the realization of these goals is affected by the variables related to the asset, such as the precision of the fundamental value. For the asset with small uncertainty about its value, the liquidity decreases with more precise public information. However, it is temporary. When all investors acquire the 
public information, the liquidity increases with the precision of public information. Hence, the regulators should require the listed companies to provide more accurate public information.

Furthermore, by endogenizing the public information acquisition, more investors could acquire the public information in period 1 when the cost is low. When the uncertainty about the asset value is small and few investors observe the public information, decreasing the cost harms liquidity. However, if the cost is low enough, there are more investors acquiring the public information (more than $\mathrm{TB}_{2}^{*}$ as stated in Corollary 2). The liquidity will increase. Therefore, the regulators should require the listed companies to disclose their information in more channels, such as newspaper, TV, and Internet to make the public information available to most investors. To achieve this goal, on the one hand, the information should be clear and easy to understand. On the other hand, the regulators should give support, such as tax benefit and loans with no or low interest, to the data companies to make their price lower and encourage more companies to develop this technology.

\section{Conclusion}

We construct a tractable REE model, in which investors have limited attention capacity to endogenize the public information acquisition and examine the implications of public information. Because of limited attention, only part of investors could acquire the public information after it is disclosed. And when public information is partly reflected in equilibrium price, it has different effect to market liquidity. When the uncertainty about the asset value is great, liquidity increases with the increase of the precision of public information and the investors acquiring public information. However, when the uncertainty about the asset value is small, the effect of public information on liquidity is different. For the precision of public information, its increase harms liquidity. With the increase of investors acquiring public information, liquidity first decreases and then increases. Endogenizing the public information acquisition shows that the mass of investors acquiring public information is negatively related to the cost. To enhance market efficiency and liquidity, the regulators should require the listed companies to disclose their information accurately by different channels as much as possible.

\section{Appendix}

\section{A. Proof of Proposition 1}

In period 1 , for $n$-investors, using the expressions of $\widetilde{v}$ and $\widetilde{s}_{p_{11}}$, we apply Bayes' rule and compute $E\left(\widetilde{v} \mid \widetilde{p}_{1}\right)=\left(\rho_{v} \bar{v}+\right.$ $\left.\rho_{s_{p_{11}}} \widetilde{s}_{p_{11}}\right) /\left(\rho_{v}+\rho_{s_{p_{11}}}\right)$ and $\operatorname{Var}\left(\widetilde{v} \mid \tilde{p}_{1}\right)=1 /\left(\rho_{v}+\rho_{s_{p_{11}}}\right)$. Plugging these expressions into demand function $D_{1 i}\left(I_{1 i}\right)$ yields the demand function $D_{1 i}\left(\widetilde{p}_{1}\right)=\left(\rho_{v} \bar{v}+\rho_{s_{p_{11}}} \widetilde{s}_{p_{11}}-\left(\rho_{v}+\rho_{s_{p_{11}}}\right) \widetilde{p}_{1}\right) /$ $\gamma$, where $I_{1 i}=\left\{\tilde{p}_{1}\right\}$. Similarly, for $p$-investors, we obtain $E\left(\widetilde{v} \mid \widetilde{p}_{1}, \widetilde{s}_{i}\right)=\left(\rho_{v} \bar{v}+\rho_{s_{p_{11}}} \widetilde{s}_{p_{11}}+\rho_{\epsilon} \widetilde{s}_{i}\right) /\left(\rho_{v}+\rho_{s_{p_{11}}}+\rho_{\epsilon}\right), \quad \operatorname{Var}(\widetilde{v} \mid$ $\left.\tilde{p}_{1}, \widetilde{s}_{i}\right)=1 /\left(\rho_{v}+\rho_{s_{p_{11}}}+\rho_{\epsilon}\right), \quad$ and $\quad D_{1 i}\left(\tilde{p}_{1}, \widetilde{s}_{i}\right)=\left(\rho_{v} \bar{v}+\right.$ $\left.\rho_{s_{p_{11}}} \widetilde{s}_{p_{11}}+\rho_{\epsilon_{1}} \widetilde{s}_{i}-\left(\rho_{v}+\rho_{s_{p_{11}}}+\rho_{\epsilon_{1}}\right) \widetilde{p}_{1}\right) / \gamma$. For $l$-investors, $E\left(\widetilde{v} \mid \widetilde{p}_{1}, \widetilde{y}\right)=\left(\rho_{v} \bar{v}+\rho_{s_{p_{12}}} \widetilde{s}_{p_{12}}+\rho_{\eta} \tilde{y}\right) /\left(\rho_{v}+\rho_{s_{p_{12}}}+\rho_{\eta}\right), \quad \operatorname{Var}(\widetilde{v} \mid$ $\left.\tilde{p}_{1}, \tilde{y}\right)=1 /\left(\rho_{v}+\rho_{s_{p_{12}}}+\rho_{\eta}\right)$, and $D_{1 i}\left(\widetilde{p}_{1}, \tilde{y}\right)=\left(\rho_{v} \bar{v}+\rho_{s_{p_{12}}} \widetilde{s}_{p_{12}}+\right.$ $\left.\rho_{\eta} \tilde{y}-\left(\rho_{v}+\rho_{s_{p_{12}}}+\rho_{\eta}\right) \widetilde{p}_{1}\right) / \gamma$. And for $p l$-investors $E\left(\widetilde{v} \mid \tilde{p}_{1}, \tilde{y}, \widetilde{s}_{i}\right)=\left(\rho_{v} \bar{v}+\rho_{s_{p_{12}}} \widetilde{s}_{p_{12}}+\rho_{\eta} \tilde{y}+\rho_{\epsilon} \widetilde{s}_{i}\right) /\left(\rho_{v}+\rho_{s_{p_{12}}}+\rho_{\epsilon}\right.$ $\left.+\rho_{\eta}\right), \operatorname{Var}\left(\widetilde{v} \mid \widetilde{p}_{1}, \tilde{y}, \widetilde{s}_{i}\right)=1 /\left(\rho_{v}+\rho_{s_{p_{12}}}+\rho_{\epsilon}+\rho_{\eta}\right)$, and $D_{1 i}\left(\widetilde{p}_{1}\right.$, $\left.\tilde{y}, \widetilde{s}_{i}\right)=\left(\rho_{v} \bar{v}+\rho_{s_{p_{12}}} \widetilde{s}_{p_{12}}+\rho_{\eta} \tilde{y}+\rho_{\epsilon} \widetilde{s}_{i}-\left(\rho_{v}+\rho_{s_{p_{12}}}+\rho_{\eta}+\rho_{\epsilon}\right)\right.$ $\left.\widetilde{p}_{1}\right) / \gamma$.

Then, substituting the above demand function, $\widetilde{s}_{p_{11}}$ and $\widetilde{s}_{p_{12}}$ in the market-clearing condition in equation (2), we get the price function as the form of equation (1), which yields the coefficients in $\widetilde{p}_{1}=\alpha_{01}+\alpha_{y 1} \tilde{y}+\alpha_{v 1} \widetilde{v}+\alpha_{x 1} \widetilde{x}_{1}$. Similarly, we obtain the detail price function in period 2 .

The coefficients are as follows: $\alpha_{01}=\rho_{v} \bar{v} /\left[\rho_{v}+\left(\mu_{l}+\right.\right.$ $\left.\left.\mu_{p l}\right) \rho_{\eta}+\left(\mu_{p}+\mu_{p l}\right) \rho_{\epsilon}+\left(\mu_{n}+\mu_{p}\right) \rho_{s_{p_{11}}}+\left(\mu_{l}+\mu_{p l}\right) \rho_{s_{p_{12}}}\right], \alpha_{v 1}=$ $\left[\left(\mu_{p}+\mu_{p l}\right) \rho_{\epsilon}+\left(\mu_{l}+\mu_{p l}\right) \rho_{s_{p_{12}}}+\left(\mu_{n}+\mu_{p}\right)\left(\rho_{s_{p_{11}}} /\left(1+\left(\alpha_{y 1} /\right.\right.\right.\right.$ $\left.\left.\left.\left.\alpha_{v 1}\right)\right)\right)\right] /\left[\rho_{v}+\mathrm{MP}\right], \mathrm{MP}=\left(\mu_{l}+\mu_{p l}\right) \rho_{\eta}+\left(\mu_{p}+\mu_{p l}\right) \rho_{\epsilon}+\left(\mu_{n}+\right.$ $\left.\mu_{p}\right) \rho_{s_{p_{11}}}+\left(\mu_{l}+\mu_{p l}\right) \rho_{s_{p_{12}}}, \alpha_{y 1} / \alpha_{v 1}=\left(\mu_{l}+\mu_{p l}\right) \rho_{\eta} /\left[\left(\mu_{p}+\mu_{p l}\right) \rho_{\epsilon}+\right.$ $\left.\left(\mu_{l}+\mu_{p l}\right) \rho_{s_{p_{12}}}\right], \alpha_{x 1} / \alpha_{v 1}=\gamma /\left(\mu_{p}+\mu_{p l}\right) \rho_{\epsilon}, \alpha_{02}=\left(\rho_{v} \bar{v}-\left(\alpha_{01} /\right.\right.$ $\left.\left.\alpha_{v 1}\right) \rho_{s_{p_{12}}}\right) /\left(\rho_{v}+\rho_{\eta}+\rho_{s_{p_{12}}}+\rho_{s_{p_{2}}}+\mu_{i} \rho_{\epsilon}\right), \quad \alpha_{v 2}=\left(\mu_{i} \rho_{\epsilon}+\rho_{s_{p_{2}}}\right) /$ $\left(\rho_{v}+\rho_{\eta}+\rho_{s_{p_{12}}}+\rho_{s_{p_{2}}}+\mu_{i} \rho_{\epsilon}\right), \alpha_{y 2}=\left(\rho_{\eta}-\left(\alpha_{y 1} / \alpha_{v 1}\right) \rho_{s_{p_{12}}}\right) /\left(\rho_{v}\right.$ $\left.+\rho_{\eta}+\rho_{s_{p_{12}}}+\rho_{s_{p_{2}}}+\mu_{i} \rho_{\epsilon}\right), \alpha_{x 2} / \alpha_{v 2}=\gamma / \mu_{i} \rho_{\epsilon}$, and $\alpha_{p 1}=\left(\rho_{s_{p_{12}}} /\right.$ $\left.\alpha_{v 1}\right) /\left(\rho_{v}+\rho_{\eta}+\rho_{s_{p_{12}}}+\rho_{s_{p_{2}}}+\mu_{i} \rho_{\epsilon}\right)$.

\section{B. Proof of Corollary 1}

$I_{1}=\left(\operatorname{var}\left(\widetilde{v} \mid \widetilde{p}_{1}\right)\right)^{-1}$ is positively related to $\rho_{s_{p_{11}}}$. Since $\partial \rho_{s_{p_{11}}} / \partial \rho_{\eta}=F Z_{1} /\left(\left(\alpha_{x 1} / \alpha_{v 1}\right)^{2} \rho_{\eta}+\left(\alpha_{y 1} / \alpha_{v 1}\right)^{2} \rho_{x_{1}}\right)^{2}$, where $F Z_{1}=\left(1+\left(\alpha_{y 1} / \alpha_{v 1}\right)\right) \rho_{x_{1}}\left(\rho_{\eta} \rho_{x_{1}} /\left(\left(\mu \rho_{\epsilon} / \mathrm{TB}_{2}\right)+\rho_{s_{p_{12}}}\right)^{2}\right)\left[\rho_{\eta}-\right.$ $\left.\left(\left(\mu \rho_{\epsilon} / \mathrm{TB}_{2}\right)+\rho_{s_{p_{12}}}\right)+\left(2 / \rho_{s_{p_{12}}}\right)\left(\left(\mu \rho_{\epsilon} / \mathrm{TB}_{2}\right)+\rho_{s_{p_{12}}}\right)^{2}\right]>0, \mathrm{~TB}_{1}$ $=\mu_{n}+\mu_{p}=1-\mathrm{TB}_{2}, \mathrm{~TB}_{2}=\mu_{l}+\mu_{p l}, A=\mu \rho_{\epsilon}+\mathrm{TB}_{2} \rho_{s_{p_{12}}}$ and $B=A+\mathrm{TB}_{2} \rho_{\eta}+\left(1-\mathrm{TB}_{2}\right) \rho_{s_{p_{11}}}$. Hence, $\left(\partial I_{1} / \partial \rho_{\eta}\right)>0$. Besides, since $\partial \rho_{s_{p_{11}}} / \partial \mathrm{TB}_{2}=\left(2 \rho_{s_{p_{11}}} \mu^{2} \rho_{\epsilon}^{2} \rho_{\eta} /\left(\left[A^{2}+\left(\mathrm{TB}_{2}\right)^{2} \rho_{\eta}\right.\right.\right.$ $\left.\left.\left.\rho_{s_{p_{12}}}\right]\left[A+\mathrm{TB}_{2} \rho_{\eta}\right]\right)\right)>0$, where $A=\left(\mu_{p}+\mu_{p l}\right) \rho_{\epsilon}+\left(\mu_{l}+\mu_{p l}\right)$ $\rho_{s_{p_{12}}},\left(\partial I_{1} / \partial \mathrm{TB}_{2}\right)>0$.

${ }^{12}$ Since $\rho_{s_{p_{12}}}=\left((\mu / \gamma) \rho_{\epsilon}\right)^{2} \rho_{x_{1}}$ and $\rho_{s_{p_{2}}}=\left((\mu / \gamma) \rho_{\epsilon}\right)^{2} \rho_{x_{2}}, \rho_{\eta}$ and $\mathrm{TB}_{2}$ donot affect $\rho_{s_{p_{12}}}$ and $\rho_{s_{p_{2}}}$. Then $\left(\partial I_{2} / \partial \rho_{\eta}\right)>0$ and $\left(\partial I_{2} / \partial \mathrm{TB}_{2}\right)=0$.

\section{Proof of Corollary 2}

For case (1), taking the differentiation with respect to $\rho_{\eta}$ yields that $\partial \mathrm{LIQ}_{1} / \partial \rho_{\eta}$ is positive related to $\mathrm{TB}_{2}^{2} \rho_{s_{p_{12}}}^{2} \rho_{\eta}^{2}+$ $2 A\left[A+\mathrm{TB}_{1} \rho_{s_{p_{12}}}\right] \mathrm{TB}_{2} \rho_{s_{p_{12}}} \rho_{\eta}+A^{2}\left[A+\mathrm{TB}_{1} \rho_{s_{p_{12}}}\right]^{2}-\rho_{v} \mathrm{~TB}_{1} \mu \rho_{\epsilon}$ $A \rho_{s_{p_{12}}}$. Hence, when $\rho_{v}$ is sufficiently small, $\left(\partial \mathrm{LIQ}_{1} / \partial \rho_{\eta}\right)>0$; while $\rho_{v}$ is sufficiently large, $\left(\partial \mathrm{LIQ}_{1} / \partial \rho_{\eta}\right)<0$.

For case (2), taking the differentiation with respect to $\mathrm{TB}_{2}$ yields that $\left(\partial \mathrm{LIQ}_{1} / \partial \mathrm{TB}_{2}\right)$ is positive related to $\left[A^{2}+\left(\mathrm{TB}_{2}\right)^{2} \rho_{\eta} \rho_{s_{p_{12}}}+\left(1-\mathrm{TB}_{2}\right) \rho_{s_{p_{12}}}\left(A+\mathrm{TB}_{2} \rho_{\eta}\right)\right]^{2}+\rho_{v} \rho_{s_{p_{12}}}$ $\left[A^{2}+\left(\mathrm{TB}_{2}\right)^{2} \rho_{\eta} \rho_{s_{p_{12}}}-2 \mu \rho_{\epsilon}\left(1-\mathrm{TB}_{2}\right) A\right]$. Therefore, when $\rho_{v}$ 
is sufficiently small, $\left(\partial \mathrm{LIQ}_{1} / \partial \mathrm{TB}_{2}\right)>0$; while $\rho_{v}$ is sufficiently large, $\left(\partial \mathrm{LIQ}_{1} / \partial \mathrm{TB}_{2}\right)>0$ is positively related to $A^{2}+\left(\mathrm{TB}_{2}\right)^{2} \rho_{\eta} \rho_{s_{p_{12}}}-2 \mu \rho_{\epsilon}\left(1-\mathrm{TB}_{2}\right) A$, which can be written as $\left(\mathrm{TB}_{2}\right)^{2} \rho_{s_{p_{12}}}\left(\rho_{\eta}+\rho_{s_{p_{12}}}+2 \mathrm{~TB}_{3} \rho_{\varepsilon}\right)+2\left(\mu \rho_{\epsilon}\right)^{2} \mathrm{~TB}_{2}-\left(\mu \rho_{\epsilon}\right)^{2}$. Then when $\mathrm{TB}_{2} \in\left[0, \mathrm{~TB}_{2}^{*}\right),\left(\mathrm{dLIQ}_{1} / \mathrm{dTB}_{2}\right)<0$; otherwise, when $\mathrm{TB}_{2} \in\left[\mathrm{TB}_{2}^{*}, 1\right],\left(\mathrm{dLIQ}_{1} / \mathrm{dTB}_{2}\right)>0$, where $\mathrm{TB}_{2}^{*}$ is the bigger solution to the above quadratic equation.

\section{Proof of Proposition 2}

For case (2), when $\left.B_{i}\left(\mu_{l}, \mu_{p l}\right)\right|_{\mu_{p l}=\mu, \mu_{l}=1-\mu}<c_{L}<B_{i}\left(\mu_{l}, \mu_{p l}\right)$ $\left.\right|_{\mu_{p l}=0, \mu_{l}=1-\mu}$, using Corollary 5 we have $\mu_{l}^{*}=1-\mu$. $\left.B_{i}\left(\mu_{l}^{*}, \mu_{p l}^{*}\right)\right|_{\mu_{l}^{*}=1-\mu}-c_{L}=0$ yields $\left(\mathrm{TB}_{2}\right)^{2} \rho_{s_{p_{12}}}\left(\rho_{\eta}+\rho_{s_{p_{12}}}\right)\left(\rho_{\eta}+\right.$ $\left.\rho_{s_{p_{12}}}-C_{1}\right)+\mathrm{TB}_{2} 2 \mathrm{~TB}_{3} \rho_{\epsilon} \rho_{s_{p_{12}}}\left(\rho_{\eta}+\rho_{s_{p_{12}}}-C_{1}\right)+\left(\mathrm{TB}_{3} \rho_{\epsilon}\right)^{2}$ $\left(\rho_{s_{112}}-C_{1}\right)=0$, where $C_{1}=\exp \left\{-2 \gamma c_{L}\right\}\left(\rho_{v}+\rho_{\eta}+\rho_{s_{p_{12}}}+\right.$ $\left.\rho_{\epsilon}\right)-\rho_{v}-\rho_{\epsilon}$. Since $\rho_{\eta}+\rho_{s_{p_{12}}}-C_{1}=\left(\rho_{v}+\rho_{\eta}+\rho_{s_{p_{12}}}+\rho_{\epsilon}\right)$ $\left(1-\exp \left\{-2 \gamma c_{L}\right\}\right)>0$, the discriminant of above quadratic equation is $4\left(\mathrm{~TB}_{3} \rho_{\epsilon}\right)^{2} \rho_{s_{p_{12}}}\left(\rho_{\eta}+\rho_{s_{p_{12}}}-C_{1}\right) C_{1} \rho_{\eta}$, which is greater than 0 . Besides, since $-(b / 2 a)=$ $\left(\left(\mathrm{TB}_{3} \rho_{\epsilon}\right) /\left(\rho_{\eta}+\rho_{s_{p_{12}}}\right)\right)<0, \quad \mathrm{~TB}_{2 *}=\mu_{l}^{*}+\mu_{p l}^{*}=\left(-2 T B_{3} \rho_{\epsilon} \rho_{s_{p_{12}}}\right.$ $\left.\left(\rho_{\eta}+\rho_{s_{p_{12}}}-C_{1}\right)+\sqrt{\Delta}\right) / \quad\left(2 \rho_{s_{p_{12}}}\left(\rho_{\eta}+\rho_{s_{p_{12}}}\right)\left(\rho_{\eta}+\rho_{s_{p_{12}}}-C_{1}\right)\right)$ is the equilibrium mass of investors investing in the technology, where $\Delta=4\left(\mathrm{~TB}_{3} \rho_{\epsilon}\right)^{2} \rho_{s_{p_{12}}}\left(\rho_{\eta}+\rho_{s_{p_{12}}}-C_{1}\right) C_{1} \rho_{\eta}>0$. And $\mu_{p l}^{*}=\mathrm{TB}_{2 *}-\mu_{l}^{*}$ is the equilibrium mass of $p$-investors investing in the technology, where $\mu_{l}^{*}=1-\mu$.

Similarly, for case (4), $\mu_{p l}^{*}=0 .\left.B_{u}\left(\mu_{l}^{*}, \mu_{p l}^{*}\right)\right|_{\mu_{p l}^{*}=0}-c_{L}=0$ yields $\mathrm{TB}_{2 *}=\mu_{l}^{*}+\mu_{p l}^{*}=\left(-2 T B_{3} \rho_{\epsilon} \rho_{s_{12}}\left(\rho_{\eta}+\mu_{s_{p_{12}}}-C_{2}\right)+\right.$ $\sqrt{\Delta}) /\left(2 \rho_{s_{p_{12}}}\left(\rho_{\eta}+\rho_{s_{p_{12}}}\right)\left(\rho_{\eta}+\rho_{s_{p_{12}}}-C_{2}\right)\right)$, where $\Delta=4$ $\left(\mathrm{TB}_{3} \rho_{\epsilon}\right)^{2} \rho_{s_{p_{12}}}\left(\rho_{\eta}+\rho_{s_{p_{12}}}-C_{2}\right) C_{2} \rho_{\eta}, \quad$ and $\quad C_{2}=\exp \left\{-2 \gamma c_{L}\right\}$ $\left(\rho_{v}+\rho_{\eta}+\rho_{s_{p_{12}}}\right)-\rho_{v}$. Since $\mu_{p l}^{*}=0, \mu_{l}^{*}=\mathrm{TB}_{2 *}$ is the equilibrium mass of $n$-investors investing in the technology.

\section{Data Availability}

No data were used to support this study.

\section{Disclosure}

The views expressed in this paper are those of the authors and do not necessarily represent the views of the Shenzhen Stock Exchange.

\section{Conflicts of Interest}

The authors declare that they have no conflicts of interest.

\section{Acknowledgments}

This work was supported by the National Natural Science Foundation of China (72001149) and the Fundamental Research Funds from Capital University of Economic and Business (Grant number: XRZ2020041).

\section{References}

[1] A. Gross-Klussmann and N. Hautsch, "When machines read the news: using automated text analytics to quantify high frequency news-implied market reactions," Journal of Empirical Finance, vol. 18, pp. 321-340, 2011.

[2] B. Han, Y. Tang, and L. Yang, "Public information and uninformed trading: implications for market liquidity and price efficiency," Journal of Economic Theory, vol. 163, pp. 604-643, 2016.

[3] D. Easley, M. O’Hara, and L. Yang, "Differential access to price information in financial markets," Journal of Financial and Quantitative Analysis, vol. 51, 2016.

[4] R. E. Verrecchia, "Essays on disclosure," Journal of Accounting and Economics, vol. 32, no. 1-3, pp. 97-180, 2001.

[5] C. Leuz and P. Wysocki, "Economic Consequences of Financial Reporting and Disclosure Regulation: A Review and Suggestions for Future Research," 2008, https://ssrn.com/ abstract $=1105398$.

[6] B. Chen, S. Liu, and Q. Zhang, "Can public information promote market stability?” Economics Letters, vol. 143, pp. 103-106, 2016.

[7] M. Amador and P.-O. Weill, "Learning from prices: public communication and welfare," Journal of Political Economy, vol. 118, no. 5, pp. 866-907, 2010.

[8] Q. Chen, Z. Huang, and Y. Zhang, "The effects of public information with asymmetrically informed short-horizon investors," Journal of Accounting Research, vol. 52, no. 3, pp. 635-669, 2014.

[9] R. J. Lundholm, "Public signals and the equilibrium allocation of private information," Journal of Accounting Research, vol. 29, no. 2, pp. 322-349, 1991.

[10] J. Dugast, "Unscheduled news and market dynamics," The Journal of Finance, vol. 73, no. 6, pp. 2537-2586, 2018.

[11] D. W. Diamond and R. E. Verrecchia, "Disclosure, liquidity, and the cost of capital," The Journal of Finance, vol. 46, no. 4, pp. 1325-1359, 1991.

[12] O. Kim and R. E. Verrecchia, "Market reaction to anticipated announcements," Journal of Financial Economics, vol. 30, no. 2, pp. 273-309, 1991.

[13] R. Lambert, C. Leuz, and R. E. Verrecchia, "Accounting information, disclosure, and the cost of capital," Journal of Accounting Research, vol. 45, no. 2, pp. 385-420, 2007.

[14] P. Kondor, "The more we know about the fundamental, the less we agree on the price," The Review of Economic Studies, vol. 79, no. 3, pp. 1175-1207, 2012.

[15] P. C. Tetlock, "Does public financial news resolve asymmetric information?" Review of Financial Studies, vol. 23, no. 9, pp. 3520-3557, 2010.

[16] S. DellaVigna and J. M. Pollet, "Investor inattention and friday earnings announcements," The Journal of Finance, vol. 64, no. 2, pp. 709-749, 2009.

[17] J. C. Johnston and H. Pashler, Attentional Limitations in DualTask Performance, pp. 155-189, Psychology Press, Hove, England, 1998.

[18] L. Peng, "Learning with information capacity constraints," Journal of Financial and Quantitative Analysis, vol. 40, no. 2, pp. 307-329, 2005.

[19] L. Peng and W. Xiong, "Investor attention, overconfidence and category learning," Journal of Financial Economics, vol. 80, no. 3, pp. 563-602, 2006.

[20] S. Van Nieuwerburgh and L. Veldkamp, "Information immobility and the home bias puzzle," The Journal of Finance, vol. 64, no. 3, pp. 1187-1215, 2009. 
[21] S. Van Nieuwerburgh and L. Veldkamp, "Information acquisition and under-diversification," Review of Economic Studies, vol. 77, no. 2, pp. 779-805, 2010.

[22] B. Biais and P.-O. Weill, "Liquidity Shocks and Order Book Dynamics," NBER Working Papers 15009, National Bureau of Economic Research, Inc., Cambridge, MA, USA, 2009, https://www.nber.org/papers/w15009.

[23] S. J. Grossman and J. E. Stiglitz, "On the impossibility of informationally efficient markets," The American Economic Review, vol. 70, pp. 393-408, 1980. 